\title{
Research on the Current Situation and Development of Sharing Economy: A Case Study of the ofo Shared Bicycle Business Model
}

\author{
Wei Weng \\ Yunnan Normal University \\ Kunming, China \\ Email: vemal@163.com
}

\author{
Qiufang Ren,Wenqin Ming and Fei $\mathrm{Li}^{*}$ \\ Yunnan Normal University \\ Kunming, China
}

\begin{abstract}
In recent year, the "Community Structured Collaborative Consumption" has continued to heat up, and various emerging internet companies have quickly attracted public attentions and capital favors. 2016 marks the very first year of development of shared bicycles. The sharing of bicycles enables people to travel more contently at the last mile, it is welcomed and supported by the public and has gained popularity in a short time. This article will employ ofo, one of the shared bicycle companies, as an example, to analyze the current status, existing problems, and corresponding solutions of shared bicycle in Kunming, in order to provide some experience for promoting the development of sharing economy.
\end{abstract}

Keywords:Collaborative Consumption, Sharing Economy, Shared Bicycle, Profit Model, Business Model

\section{INTRODUCTION}

The sharing economy generally refers to a new business model with a certain amount of remuneration as its main purpose, and temporarily transfers the right to use to strangers. Its essence is to integrate offline idle goods or service providers, allowing them to provide products or services at a lower price. During the transaction process, the supplier obtains certain amount of money by transferring the right to use the goods or providing services within a certain period of time. In return, the demanding party does not own the ownership of the item directly, but uses the item by sharing, renting, borrowing, etc.

The ofo's yellow bicycle pioneered the "dockless shared bicycle" model, and became the world's first platform for sharing bikes without docks. Customers use the company's mobile app or other collaborative apps such as WeChat and Alipay on their smartphones to locate nearby bicycles. Each bike has a QR code on the frame, which the customer scans to unlock the bike anywhere and anytime. The customer may also participate in the " 1 to N" Program, by sharing their own bike with the ofo sharing platform, they will have free access to all ofo's shared bikes.

\section{ANALYSIS OF THE DEVELOPMENT STATUS OF OFO SHARED BICYCLES}

Dai Wei, graduated from Peking University, co-founded ofo with other four partners in 2014. It was the very first company that create the dockless shared bicycle model, the first domestic bike sharing company, and also for the first time to use universities as an extension, and then gradually to the public. It employs a bicycle as a physical product and adopts smartphone APP to scan and rent it. On September 26 2016, ofo was invested in tens of millions of dollars by DiDi; Lhasa became the 100th city where ofo operates; one month later the deposit was raised from 99 yuan to 199 yuan. Then, to further changes were made to improve the appearance of the products. The "ofo bigeye" bicycle was launched. On the 1st of July of the same year, ofo had completed the 5th round financing of over 700 million U.S. dollars.

Compared with 2016, the year-on-year market penetration growth rate of ofo and Mobike was $1811.7 \%$ and $482.5 \%$ respectively, the annual growth rate of ofo was nearly 4 times that of Mobike. ofo ranked first in the growth rate of China's App market penetration index, and it had become the fastest growing App in 2017.

Surely, with the massive market share of ofo, the parking of bicycles has also become a big issue. Due to the dockless mode, customers may park anywhere they prefer, as the volume of bicycle deployments continues to increase, the parking has become more disorder and chaotic, resulting heavier cost and burden of urban management for the government sectors.

\section{ANALYSIS OF THE PROFIT MODEL OF OFO SHARED BICYCLE}

Compared with the traditional business model, because the shared bicycle industry occupies both the supply side and the platform side, the profitability model of such industry combines the characteristics of the traditional rental industry profit model and the profitability model of the internet sharing platform. In other words, idle bicycles are gathered and leased out through Apps and other online channels. So far, the profitability models of shared bicycle companies are generally as follows:

\section{A. The Deposit}

Deposit is refundable. Therefore most people will not resist paying;

The deposit can be refunded, if only the customers take the initiative to request, and the company will release the deposit within a few working days, but most customers do not prefer to do so, once refunded, they will have to pay the deposit again for the next shared bicycle. As a result, a fairly large amount of capital is deposited in the company, which is equal to free occupation;

The deposit cannot be used as rent; 
The deposited account is not bound to a specific bicycle, which means each deployed shared bike may attract far more than one deposit.

\section{B. The Rent}

Part of the profits of shared bicycles comes from timeshare leasing. Most of the companies have their rent controlled under 1 yuan per hour. Although the total daily volume of rent is huge, the price is too low. According to Tencent Technology, the average usage frequency of shared bicycles has fallen back to twice a day, without considering subsidies income, take the highest price of 1 yuan/hour, an average daily income of 2 yuan per bicycle can be earned. Furthermore, there may be approximately 270 days of effective riding a year taking out days with extreme weather conditions, multiplied by the income of 2 yuan/day, the annual income of a shared bicycle will be approximately 500 yuan, give or take.

Shared bicycle as a common service method, it is possible for people to employ their personal experiences to replace the data analysis, but still there's a need to measure whether the shared bicycle is profitable. As with the continuous development of shared bicycles, all major companies have proposed a credit based deposit free service, it is important to calculate profitability of shared bicycle itself only considering rent factor, the cost of bicycle refers to the following equation:

Cost of bicycle $=[$ cost of production/ $(1$ - damage rate $) /$ (1- maintenance cost rate) - cost of production] + depreciation expense (excluding the depreciation expense of lost $)+$ deployment $\&$ logistics expenses.

The first is the revenue analysis of the ofo shared bicycle, and assume that the annual revenue of a ofo shared bicycle is 500 yuan (according to the statistics, each ofo shared bicycle could be employed 4 times a day averagely at a rent rate of 0.5 yuan per time, resulting an daily revenue of 2 yuan; there are approximately 250 days a year, excluding days with extreme weather conditions).

The next is to analyze the cost of the bicycle. As ofo chooses a asset-light strategy, its shared bicycles come from donations or bicycle manufacturers, the cost of production is low, leads to the quality of the bicycles which is criticized by the public, they can be easily damaged or stolen. Based on these, the following assumptions can be made: the production cost of each bicycle is 300 yuan, the depreciation period is 2 years, both damage rate and maintenance cost rate are $20 \%$, ignoring the net output value (the net residual value is 0 ), and the deployment \& logistic expense is 10 yuan; the calculation is as follow:

Cost of bicycle $=[$ cost of production/ $(1$ - damage rate $) /$ (1- maintenance cost rate) - cost of production] + depreciation expense (excluding the depreciation expense of lost $)+$ deployment $\&$ logistics expenses.

$$
\begin{aligned}
& =[300 /(1-20 \%) /(1-20 \%)-300]+[300 *(1- \\
& 20 \%)] / 2+10 \\
& =298.75
\end{aligned}
$$

The annual income of each ofo shared bicycle $=500$ (the annual revenue) -298.75 (the cost of bicycle) $=$
201.25 yuan; the operating profit margin could reach $40.25 \%$.

\section{Platform Services}

The ofo shared bicycle company has gathered a great number of users through internet platforms such as smartphone App. The mid-term profit opportunity lies of the industry in how to take this advantage into integrating public livelihood services and creating its own business ecosystem. Business partners in various industries can integrate short-distance travel services into their own Apps through an open internet-based platform. This allows users to conveniently access bicycle at any time, in order to increase customer stickiness; as to shared bicycle companies, the service can be extended to various life scenarios while also helping to establish its own ecosystem. The development of ofo shared bicycle can refer to the development pattern, to integrate various industrial applications via sharing platforms, and then to jointly create a multi-level ecosystem service system.

\section{CONCLUSION}

Although ofo shared bicycle hasn't explored a healthy and sustainable profit model yet, the concept of green travel undoubtedly caters to the future direction of public transportation. Whether or not shared bicycles can achieve sustainable development is not only a commercial issue but also a sociological one. To uncover a sustainable profitability pattern of the industry in question, it is necessary to explore various approaches. In particular, civic awareness and social awareness are noteworthy. Shared bicycles should not only be treated as a mean of transportation, but also be regarded as a social consensus, in order to achieve a healthy, ecological and sustainable lifestyle.

\section{REFERENCES}

[1] Lidong Wang. "The Hidden Troubles in the Development of Sharing Economy", Brand. 08(2015), 235

[2] Yunyun He, Yajie Sun. "Disputes Arising from Tailored Taxi Service under the Theory of Sharing Economy", Business. 06 (2015), 256

[3] Qingli Tang. "The Regulation Path of Sharing Economy, Tailored Taxi Alike", China Legal Science. 04 (2015), 286-302

[4] Yue Peng. "The Legal Regulation of Sharing Economy: A Case Study on Internet Chauffeured Car Service". Administrative Law Review. 01 (2016): 117-131

[5] Yi Liu, Jiechang Xia. "Research on the Theory and Policy Trend of Sharing Economy", Economic Perspectives. 04 (2016), 116-125

[6] Qiang Ma. "Development Status, Bottlenecks and Countermeasures of Sharing Economy in China", Modern Economic Research. 10 (2016), 20-24

[7] Xiwen Wang. "How Can Public Innovations Be Possible - The Physical Information Sharing Economy in the Internet Era", People's Tribune. Frontiers. 12 (2015), 25-31, 91

[8] Wensheng Peng \& etc. "Sharing Economy Is the New Growth Point". The Chinese Banker. 10 (2015), 64-67

[9] Zhilai Zheng. "Research on the Cause, Connotation and Business Model of Sharing Economy", Modern Economic Research. 3 (2016), 32-36

[10] Nan Cheng, Yanquan Hou. "Uber's Dilemma", The Internet Economy. 05 (2015), 74-79 